
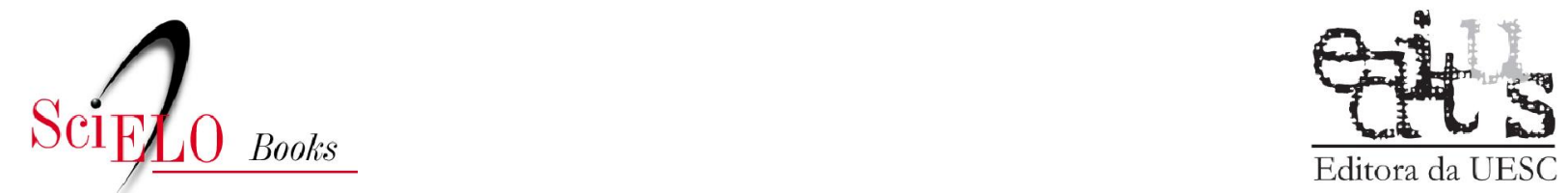

\title{
Pesquisa histórica
}

\author{
uma experiência em ato
}

Raimunda Alves Moreira de Assis

\section{SciELO Books / SciELO Livros / SciELO Libros}

ASSIS, R. A. M. Pesquisa histórica: uma experiência em ato. In: MORORÓ, L. P., COUTO, M. E. S., and ASSIS, R. A. M., orgs. Notas teórico-metodológicas de pesquisas em educação: concepções e trajetórias [online]. Ilhéus, BA: EDITUS, 2017, pp. 41-54. ISBN: 978-85-7455-493-8. Available from: doi: 10.7476/9788574554938.002. Also available in ePUB from: http://books.scielo.org/id/yjxdq/epub/mororo-9788574554938.epub.

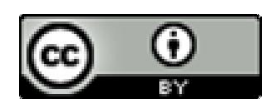

All the contents of this work, except where otherwise noted, is licensed under a Creative Commons Attribution 4.0 International license.

Todo o conteúdo deste trabalho, exceto quando houver ressalva, é publicado sob a licença Creative Commons Atribição 4.0.

Todo el contenido de esta obra, excepto donde se indique lo contrario, está bajo licencia de la licencia Creative Commons Reconocimento 4.0. 


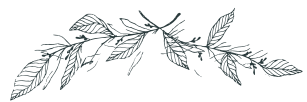 \\ PESQUISA HISTÓRICA: UMA EXPERIÊNCIA EM ATO}

Raimunda Alves Moreira de Assis ${ }^{1}$

Ao aceitar o convite para participar desse trabalho coletivo que tem como objetivo registrar as experiências vivenciadas por um grupo de doutorandas sobre os seus percursos formativos enquanto pesquisadoras, procurei acolher a proposta como um grande desafio a ser explorado e optei por traçar o caminho metodológico, que trilhei, com destaque para os métodos e as técnicas de investigaçáo científica.

Considero um trabalho relevante porque ele poderá oferecer contribuiçôes significativas para os jovens pesquisadores que estão iniciando as suas primeiras experiências no caminho investigativo, já que retratam casos concretos vividos por outros pesquisadores. Além do mais, os estudos apresentam subsídios para a escolha do campo de estudo, formulação da questão de pesquisa e elaboração dos objetivos, bem como a opção por um itinerário metodológico, ficando claro que o método não se constitui em uma camisa de força e que a sua escolha dependerá das características do objeto de estudo.

É com este intento que pretendo relatar a minha experiência no campo da pesquisa histórica e, assim, contribuir para o aprofundamento das discussóes que serão travadas aqui, bem como motivar os jovens pesquisadores a desenvolverem estudos na área da História da Educação e, particularmente, na História da Educação Regional.

De modo a atender às intençóes apresentadas anteriormente, organizei este texto em três partes. No primeiro, discutirei a

1 Professora na Universidade Estadual de Santa Cruz - UESC.

E-mail assisraimunda @hotmail.com 
importância de se pesquisar e estudar História da Educação nos cursos de formação de professores. Em seguida, comentarei brevemente sobre o conceito que atribuímos às palavras historiografia e fonte na pesquisa histórica em razão dos vários sentidos que estes termos assumem. E, por último, descrevo a vivência empírica com a pesquisa realizada no doutoramento a partir do método da pesquisa histórico-documental. A expectativa é de que os relatos apresentados possam servir de parâmetro para os novos pesquisadores que desejam caminhar na área da pesquisa histórica documental no campo da educação.

\section{Por que estudar história da educaçáo nos cursos de formação de professores?}

Após uma pesquisa exploratória sobre a temática da história da educação no Município de Itabuna-BA, com a finalidade de identificar as produçóes existentes para organizar as informaçóes e promover a evolução da pesquisa, percebi a inexistência de estudos sistematizados sobre este campo do conhecimento. Daí, então, comecei a refletir: como um trabalho na linha da história da educação poderia ser importante para ampliar o conhecimento dos professores na direção da sua formação, sendo vistos enquanto sujeitos produtores da história?

A constatação desta realidade causou-me um grande conflito, passando a ser uma forte motivaçáo para realizaçáo do estudo. E a partir das leituras e experiências empíricas, fui percebendo o quanto seria importante um trabalho sobre esta temática para auxiliar os estudantes e professores nos seus estudos, de modo a terem a compreensão da importância de se conhecer o passado e apreender as mudanças que aconteceram e acontecem na educação até os dias atuais.

$\mathrm{O}$ anúncio dessas preocupaçóes também é aludido pelo autor português Antonio Nóvoa, quando declara que a história nos ajuda a refletir sobre o processo educacional e cabe ao educador 
estudá-la para perceber que o passado deve ser compreendido como representação de construçóes humanas e, a partir destas análises, compreender o futuro (NÓVOA, 2005). O mesmo autor ainda aponta a história da educação como uma das disciplinas que pode ser considerada fundadora das ciências da Educação, pois na sua origem ela traz consigo a "preocupação com a educação enquanto ação humana intencional baseada em princípios científicos" (NOVOA apud FAVARO, 2011, p. 1).

Pesquisadores do campo da História da Educação, como Stephanou e Bastos (2009) Gatti (2008), Saviani (2007), Nóvoa (1997) e muitos outros, defendem o estudo da história da educação nos cursos de formação como possibilidade de ampliação no processo de conhecimento. Eles afirmam que esse estudo permite ampliar o olhar reflexivo sobre a origem dos discursos historiográficos na educação em cada período histórico a partir das suas múltiplas manifestaçóes. Logo, devemos compreender que para estudar o passado histórico é preciso analisar os vestígios deixados em um espaço-tempo, em cada momento histórico, considerando-se a sua relação dialética com a sociedade, com a cultura, enfim, com o homem. Em suma, a educação não tem um fim em si mesma, ela atende os interesses de uma dada sociedade a partir de suas visóes de homem e de mundo de um determinado período histórico, numa relação entre fatos passados e presentes, "não como uma investigação do passado em si, mas de indícios a partir dos quais o historiador interpreta o passado" (ABBUD, 2008 p.6).

Apoiando-me em Nóvoa (2009), busquei resposta para o questionamento levantado inicialmente a respeito da importância de estudar história da educação nos cursos de formação de professores. $\mathrm{O}$ autor aponta quatro premissas que dão sustentação a nossa análise. $\mathrm{Na}$ primeira, ele aponta que é para cultivar um saudável ceticismo. Ao elucidar que o campo da educação convive com o mundo das "novidades" (novos métodos, reformas, tecnologias etc.), ou seja, há uma busca pelo novo, mas tudo continua no mesmo. A segunda proposição é a questão da lógica das identidades múltiplas; o autor 
defende que a história da educaçáo deve ser estudada porque, se de um lado, tem-se o processo de globalizaçáo que propicia uma desenraizada movimentaçáo de ideias e conceitos, do outro se defende as identidades locais e regionais de variadas naturezas. Diante deste "aparente" antagonismo, cabe ao educador perceber esta lógica das "múltiplas identidades" e intermediar o trabalho educativo, elucidando os processos formativos. Em outras palavras, o educador deve possuir um conhecimento que possibilite ter atitudes críticas e reflexivas sobre o processo de construção de uma dada realidade histórica.

Outra premissa apresentada pelo autor é a de que se estuda a história da educação para pensar os indivíduos como produtores de história. Ele aponta "que somos criadores, e não apenas criaturas, da história” (NÓVOA, 2009, p.11) e que a reflexão histórica não serve somente para descrever o passado, mas também para nos fazer refletir sobre um patrimônio cultural de projetos e de experiências de forma criteriosa. E, por fim, elucida que a história da educação é para explicar que não há mudanças sem história e que a todo momento estamos diante de experiências que se ampliam, produzindo memória histórica a partir de uma compreensão dos fenômenos educativos.

Além do que já foi apontado, parece-me relevante outra constatação de Saviani (2007), quando expõe que é importante estudar história da educação pela necessidade de relacioná-la com as políticas educacionais. Argumenta que

a história da educação, enquanto repositório sistemático e intencional da memória educacional será uma referência indispensável na formulação da política educacional que se queira propor de forma consistente, em especial nos momentos marcados por intentos de reformas educativas (SAVIANI, 2001 apud GATTI Jr 2008, p. 228).

Trata-se, portanto, de entender que a obtenção dos conhecimentos históricos permitirá uma melhor articulação na formulação das políticas públicas educacionais. E foi nesta direção que 
arrisquei desenvolver o estudo sobre a reconstituição da trajetória histórica da educação no Município de Itabuna, no período entre 1906 a 1945. Assim, amparada nas afirmaçóes anteriores, foi possível compreender a pertinência do nosso estudo e destacar o quanto estas análises são importantes para que não se perca de vista a construção do processo histórico, e mais: que se busque pensar a formação docente analisando os variados pontos de vista e reflexôes que constituem fundamentos para o processo de elaboração da historiografia da educação brasileira com a apreensão de que são os homens quem fazem a história.

\section{Historiografia da educaçáo e as fontes históricas}

Historiografia é uma palavra que se apresenta com várias conotaçôes entre os historiógrafos e, no decorrer do seu processo histórico, o vocábulo foi assumindo diferentes conceitos e comportamentos distintos. Para compreender estas variaçóes de significado, os estudos de Lombardi (2004) foram fundamentais, quando esclarecem que o termo foi criado para solucionar a ambiguidade atribuída à palavra História.

Lombardi (2004) firma que o termo historiografia é usado para designar o conhecimento histórico produzido. Acrescenta, ainda, que etimologicamente a palavra resulta da composição de dois termos: graphia e história, significando, na língua portuguesa, escrita da história (LOMBARDI, 2004, p.152). Vale ressaltar que, ainda hoje, o termo se apresenta de forma ambígua e isso decorre, sobretudo, das opçóes teórico-metodológicas dos pesquisadores.

No Brasil, podemos destacar estudiosos importantes, dessa área, que expóem diferentes enfoques na construção da historiografia educacional, a exemplo de Warde (1990), Lombardi (2004), Saviani (2000), Clarice Nunes (1995), Vidal e Faria Filho (2003), Sanfelice (2004), dentre outros. Os autores, em geral, apresentam posicionamentos teóricos definidos e perspectivas epistemológicas 
distintas nos seus estudos. Contudo, há um respeito mútuo, porque o que os une é o desejo de promover o desenvolvimento dos estudos no campo da historiografia educacional brasileira, acatando as opçóes teórico-metodológicas de cada pesquisador.

\subsection{As fontes históricas}

É importante observar que a palavra fonte apresenta vários significados. Segundo Saviani (2007), um deles denota aquilo que origina ou produz, ou seja, a nascente, o miradouro, o lugar onde brota a mina. Por outro lado, tem o sentido de base, ponto de apoio, de informaçôes. Além disso, podemos compreender a palavra fonte como um sistema coeso de conhecimentos que se "liga a um repositório abundante de elementos que atendem a determinada necessidade" (SAVIANI, 2007, p. 28). No campo da história, o termo é aplicado com sentido analógico, ou seja, como ponto de apoio para construção do objeto histórico. Tal raciocínio deixa claro que as fontes são produtos históricos, construídas pela ação humana. Confirmando este entendimento, Lombardi afirma que

as fontes resultam da ação histórica do homem e, mesmo que náo tenham sido produzidas com a intencionalidade de registrar a sua vida e o seu mundo, acabam testemunhando o mundo dos homens em suas relaçóes com outros homens e com o mundo circundante, a natureza, de forma que produza e reproduza as condiçóes de existência e de vida (LOMBARDI, 2004, p.155).

De acordo com este pressuposto, entendemos que as fontes da História são construídas pela ação dos homens que nascem enquanto testemunhos dos atos históricos produzidos pela humanidade. Nesta direção, ao iniciar a pesquisa exploratória dos documentos, todas as fontes que encontramos nas suas mais diferentes formas de registro, se constituíram em documentos. 
Foi com este fundamento que elaboramos a compreensão de que os documentos não falam por si só. As informaçôes são mediadas pelo pesquisador que, na sua postura investigativa, imprime o seu ser; a sua forma de ler o mundo. E com esta atitude de busca, de desvendar dados, de procurar explicaçóes para o não explicado, relatarei o meu processo investigativo dentro da linha da pesquisa histórica enquanto política pública.

\section{A pesquisa histórica documental: o relato de uma experiência}

Vale a pena registrar que o meu olhar para a pesquisa, na perspectiva histórico/documental, teve início no Mestrado em Educação, UESC/UFBA, no ano 2000, por sugestão da professora Alda Pepe, na época, Coordenadora do Programa de Pós-Graduação, estabelecido para promover a formaçáo dos docentes do quadro da Universidade Estadual de Santa Cruz (UESC).

Cursar o mestrado, naquele momento, significava entrar no mundo da pesquisa institucional, algo que ainda não era táo comum na minha prática docente. Inicialmente, muitas foram as inquietaçóes sobre a falta de tempo; carga de trabalho duplicada; recursos financeiros, viagens e outros. Estas questóes se juntavam a outras de cunho teórico-metodológico, ligadas ao projeto, até então embrionário e que precisava ser construído e se desenvolver.

Nessa direção, em uma das conversas com a coordenadora do curso, ela propôs o desafio de realizar um estudo sobre a história da educação. Embora percebesse a importância da proposta, estava certa dos dilemas e dificuldades a serem enfrentados. De fato, a partir daí foram muitas as dúvidas e questôes a encarar. A primeira delas relacionava-se aos próprios desafios de qualquer pesquisa científica, além do medo próprio e das incertezas de todo pesquisador iniciante, que, em geral, expressa as suas angústias ao atentar para as questôes básicas de qualquer pesquisa, como por 
exemplo: por onde começar? Qual o caminho a seguir? Quais as fontes? Após essas e outras incertezas, realizei uma longa conversa com a minha futura orientadora, Professora Dra. Marli Geralda, e definimos, provisoriamente, o objetivo de estudo com as questóes basilares: pesquisar o Quê? Quem? Onde? Quando? Como? Por quê? E, a partir daí, elaboramos um roteiro de estudo para começar o desenvolvimento do trabalho.

Definido o campo de pesquisa, o primeiro passo foi realizar o levantamento das fontes de informaçôes existentes para servir de ponto de apoio para a construçáo do objeto de estudo cuja decisão foi realizar a análise dos documentos por compreendê-los como produto histórico derivado das açóes humanas e que podem revelar as suas ideias, opinióes. Em outras palavras, noticiam as formas de atuar e viver de um povo, construídas nas suas múltiplas relaçóes e expressas nas mais diferentes formas de registros, e que foram se formulando e guardadas em um determinado momento histórico (SAVIANI, 2007). Daí, eu passei a visitar os variados espaços públicos e privados, como as escolas, igrejas, bibliotecas, residências e prefeitura, além de pessoas da comunidade que poderiam dispor de documentos para complementar a investigação. No início das investidas não obtive o sucesso esperado, mas a busca persistia. E, desta feita, visitei a Câmara de Vereadores e o Arquivo Público Municipal de Itabuna (APMI) e, finalmente, se consolidava a possibilidade de realização da pesquisa pela quantidade significativa de documentos, de naturezas diversas, existentes neste espaço público.

Decerto, o Arquivo Público Municipal de Itabuna (APMI) se constituiu no principal local de pesquisa por abrigar uma coleção de fontes primárias importantes. Esta coleção abrigava uma diversidade extraordinária de documentos, principalmente as fontes escritas, que passaram a dar mais clareza para o entendimento do registro dos acontecimentos históricos no período em estudo.

Após os primeiros procedimentos de aproximação com este espaço, realizei contato formal com a Diretoria para obter informa- 
çôes sobre os procedimentos de funcionamento; horários de visitas; contatos com os funcionários, procedimentos técnicos etc. Desse modo, passei a frequentar o Arquivo e a realizar as atividades de seleção dos documentos. Inicialmente, fiz a leitura dos documentos para que fosse possível escolher aqueles que apresentavam dados importantes para a investigação.

Logo em seguida, iniciei o desenvolvimento do trabalho analítico, utilizando, como fonte principal, os documentos dos livros de Atas do Conselho Municipal, organizados sequencialmente por ano, além do Jornal Oficial do Município e de outros impressos de circulação local. No total, consultamos um conjunto com mais de 20 tipos de fontes, distribuídos em uma média de 1.100 documentos manuscritos, impressos e iconográficos. Destaquei, principalmente, os jornais oficiais, os livros de registro de atas, decretos, leis, regulamentos, correspondência pública, fotografias e outros. Esta pré-análise foi importante para gerenciar o tempo disponível para a pesquisa e identificação do material recolhido (ASSIS, 2006).

A coleta de dados no Arquivo Público de Itabuna e em outros espaços privados teve um tempo médio de 11 a 12 meses. As tarefas eram realizadas pela pesquisadora e por uma bolsista, Luciana Lavigne. Juntas, diariamente, desenvolvíamos leituras, de forma prudente e criteriosa, com a intenção de exercitar a compreensão sobre as possibilidades de usar os distintos tipos de fonte encontrados para realizar o trabalho.

Ao selecionar as informações, fazia-se a transcrição literal de todos os subsídios indispensáveis para o desenvolvimento da pesquisa, tendo em mente que a construção da sociedade é resultado das açôes e decisóes humanas, e que cada um de nós participa de alguma forma dessa construção. E com esta compreensão buscavam os fatos relativos à vida cotidiana: fatores políticos, econômicos, sociais, culturais, ideológicos e educacionais, sempre procurando estabelecer a relação e a repercussão dos acontecimentos na própria história.

Para a produção do texto, as informaçóes receberam um tratamento com enfoques quantitativo e qualitativo. Os dados quantitativos foram 
analisados e organizados sob a forma de gráficos. A análise qualitativa foi embasada nos discursos presentes nos documentos, levando em conta que o ser humano não é passivo, que o estudo da experiência humana deve ser feito entendendo que as pessoas interagem, interpretam e constroem sentidos para o mundo em que vivem continuamente. Dessa forma, a análise de conteúdo surge como uma técnica mais elaborada da observação documental, sendo utilizada como meio para estudar as comunicaçóes entre os homens. Em outras palavras, recorremos ao conteúdo das mensagens presentes nos documentos, fundamentadas nos pressupostos de uma concepção crítica e dinâmica da linguagem que, por sua vez, é compreendida como forma de expressão de representaçóes sociais historicamente constituídas acerca da realidade social vivida por determinado grupo e expressas nos documentos produzidos (FRANCO; 2003; BRAVO, 2007; MINAYO, 2007).

De acordo com este entendimento, os documentos foram analisados minuciosamente, buscando interpretar o conteúdo das mensagens e dar respostas à problemática que motivou a pesquisa. Após esses procedimentos técnicos e sistemáticos da investigação, considerando-se os objetivos, procurei organizar e analisar os dados a partir da definição de unidades temáticas, denominadas de aspectos da infra-estrutura da cidade; aspectos socioculturais e aspectos econômicos, organizados em grandes categorias, a saber: Conjuntura Política Brasileira e a Educação Escolar: 1930/1945; Movimento Renovador na Educação e o Pensamento Educacional no Município de Itabuna; A Educação no Município de Itabuna: 1930/1945; A Organização do Ensino em Itabuna e Aspectos da Cultura Escolar.

As categorias anteriormente elencadas se subdividiram de acordo com outros elementos singulares da investigação que, aos poucos, foram se constituindo num corpo sólido de informaçóes, permitindo que o fio condutor da análise de dados seguisse uma perspectiva compreensiva, hermenêutica; na linha do que assinala Diniz (2008, p. 57), "tentando desvendar o conteúdo latente, iluminado pela teoria". O resultado deste trabalho foi a produçáo da tese que reconstituiu a trajetória histórica da educação do município de Itabuna. 
Para finalizar, considerei interessante destacar a importância e os limites que uma pesquisa de natureza histórico documental impóe aos pesquisadores. No caso específico do município de Itabuna, o valor do trabalho reside no fato de ser o primeiro a ser desenvolvido de forma sistemática no campo da educação. Ao lado disso, emerge o meu sentimento de alegria por ser a primeira pesquisadora a "garimpar" fontes primárias sobre parte da História da Educação do Município de Itabuna, dando início à produção da historiografia educacional na Região. Como desvantagem, destaco as parcas condiçōes que são oferecidas para guarda dos documentos nos variados espaços, muitas vezes armazenados de forma inadequada e desorganizada, amontoados dentro de caixas, fato que dificulta, ainda mais, o acesso, a conservaçáo e acelera seu desaparecimento.

\section{Consideraçóes finais}

Foram constantes as preocupaçóes e os desafios quando nos propusemos a pesquisar. As indagaçóes como o para quê, para quem e como pesquisamos aumentavam cada vez mais, transformando a vida do pesquisador iniciante em um verdadeiro pesadelo. Os principais comentários que ouvia dos colegas mais adiantados eram sobre as renúncias diárias da convivência com amigos, família, lazer e outras. Tudo isso em razáo da sobrecarga de estudos para atender às demandas de um curso de pós-graduaçáo marcado pela exigência de publicaçóes e pelos prazos a serem cumpridos.

Outros desafios ocorreram, sendo o mais importante a tentativa de responder o porquê da escolha do tema e para que estudar história da educação nos cursos de formação de professores. Da incessante conversa com os autores, compreende-se que a educaçáo tem por objetivo formar cidadáos conscientes. E, portanto, o estudo crítico da história é sem dúvida um dos elementos essenciais na formação do cidadáo com capacidade de participar conscientemente da transformação da sociedade e do mundo em que vive. 
Ainda sob esse ponto de vista, estou convencida da importância da temática, da contribuição que o resultado do estudo trará para a comunidade acadêmica e para os estudantes sobre a política educacional implementada no Município de Itabuna no período analisado. $\mathrm{O}$ que se pode concluir, a partir da experiência de realizar uma pesquisa no campo da história da educação, é que essa atividade se constituiu num verdadeiro ato de "caça ao tesouro", cercado pelas múltiplas incertezas sobre qual a melhor trilha a seguir. Todavia, o desejo de construir o original, o inédito, nos motivou a continuar na luta para ultrapassar as barreiras encontradas no percurso e descobrir outras passagens que possibilitassem a efetivação do objetivo almejado. Nesse sentido, mantive-me firme na tarefa de pesquisar, de me constituir autora de um movimento permanente da construção do vir a ser da historiografia da educação do Município de Itabuna-BA, até então inexistente. 


\section{REFERÊNCIAS}

ASSIS, R.A. M. de. A educaçáo em Itabuna: um estudo de organização escolar: 1906-1930. Ilhéus, BA: Editus, 2006.

ABBUD, Maria Luiza Macedo. A história da educação como disciplina nos cursos de formação de professores. Anais... ANPED SUL 2008. VII Seminário de Pesquisa da Região Sul. UNIVALI/Itajaí - SC. jun.2008, p.1-8.

DINIZ, D. M. 'E o que é o professor, na ordem das coisas?' Docência de primeiras letras no Ceará imperial. Dissertação (Mestrado Acadêmico em Educação). Universidade Estadual do Ceará, Fortaleza, 2008.

ECO, Umberto. Como se faz uma tese. 14. ed. São Paulo: Perspectiva, 1977.

FAVARO, M.R.G. O ensino de História da Educação no curso de Pedagogia da Universidade Estadual de Londrina . Anais... VI Congresso Brasileiro de História da Educação - invenção, tradição e escritas da História da Educação no Brasil, 2011, Vitória-ES.

FRANCO, M. L. P. B. Análise de conteúdo. Brasília: Plano editora, 2003.

GATTI, B. A; SIQUEIRA. E. de Sá; ANDRÉ, M. E. D. A. Políticas

docentes no Brasil: um estado da arte.- Brasília: UNESCO, 2011.

GATTI, B; et all. Formaçáo de professores para o ensino fundamental: instituições formadoras e seu currículo. Relatório de Pesquisa. São Paulo: Fundação Carlos Chagas; Fundação Vitor Civita, 2008, 2v.

GOMES, R. Análise e interpretação de dados de pesquisa qualitativa. In.: DESLANDES, S. F; GOMES, R.; MINAYO, M. C. S.(org). Pesquisa social: teoria, método e criatividade. 26 ed. Petrópolis, RJ: Vozes, 2007. P. 79-108. 
GOMES, R. História da história da educação no Brasil: um balanço prévio e necessário. EccoS - Revista Científica, São Paulo, v. 10, n. especial, p. 147-167, 2008.162.

LE GOFF, J. História e memória. Tradução Bernardo Leitão [et. all.]. 4a ed. Campinas, São Paulo: Editora da UNICAMP, 1996 (Coleção Repertórios).

LOMBARDI, J. C.; NASCIMENTO, M.I.M. (Orgs.). Fontes, história e historiografia da educaçáo. Campinas, SP: Autores Associados, 2004.

NÓVOA, A. Apresentação: Por que a história da educação?. In: STEPHANOU, Maria; BASTOS, Maria H. C. (Orgs.). Histórias e memórias da Educaçáo no Brasil, vol. II: Séc. XIX.Petrópolis, RJ: Vozes, 2009.

Formação de professores e profissão docente. In: NÓVOA, A. (Coord.). Os professores e sua formaçáo. 3. ed. Lisboa: Dom Quixote, 1997. p. 9-33.

SAVIANI, D. Breves consideraçóes sobre fontes para a história da educação. Revista HISTEDBR On-line, Campinas: SP. n. especial, p. 28-35, ago. 2006.

Pedagogia: o espaço da educação na universidade. In: Cadernos de Pesquisa. v. 37, n. 130, p. 99 - 134. jan/abr. 2007.

STEPHANOU, Maria. e BASTOS, Maria Helena Camara (Orgs.). Histórias e memórias da Educação no Brasil - Vol. II - Séc. XIX. 3. Ed. Petrópolis, RJ: Vozes, 2009. 